Список литературы:

1. Министерство Образования и Науки Российской Федерации: http://минобрнауки.pф/

2. Образовательный центр: http://student45.ru/why-studying/foreign-languageand-job/

\title{
Формирование образного мышления на уроках истории и обществознания
}

\author{
Хованский В.П., учитель \\ истории и обществознания, \\ МБОУ Русская классическая гимназия № 2, \\ E-mail: v.khovanskiy.66@mail.ru
}

В настоящее время плотность информационного потока настолько велика, что мы не в состоянии осознать многие общественные явления. В связи с этим нарастает психологическая перегрузка при обучении, сопровождающаяся общим снижением здоровья населения.

Было время, когда несколько поколений людей могли успешно пользоваться практически одними и теми же знаниями, необходимыми в профессиональной деятельности. В настоящий момент за время жизни одного поколения происходит 4-5 кардинальных обновлений технологий и связанных с ними знаний, и этот процесс ускоряется. Теперь специалисту для сохранения своей профессиональной компетентности необходимо каждые 5-7 лет обновлять свои знания. Стал расти объём базисных знаний в школе и вузах и, как следствие, увеличилась нагрузка на память. В этой ситуации включаются защитные механизмы мозга и всё чаще отключаются каналы восприятия информации. А «всякий слышит лишь то, что понимает», как выразился Плавт.

Так «кто же виноват» и « что делать»?

Ядром педагогики бесспорно является технология процесса обучения. «Инноваций» в последние годы было много, вот только ситуация не меняется, а скорее наоборот, усугубляется. Так что же такое собственно обучение? А это ведь «целенаправленное, регулируемое информационное воздействие на мозг с целью реализации его функциональных возможностей», т.е. развитие, совершенствование мышления, памяти, речи и т.д. Видны ключевые понятия: воздействие - мозг развитие.

Традиционные и разные «инновационные» методики обучения зачастую не используют знания из области нейронауки. Поэтому попытки реорганизации обучения не дают ощутимых результатов.

Наш мозг состоит из двух частей, двух полушарий, плотно прилегающих друг к другу внутри черепной коробки и соединённых пучками нервных волокон. Мозг, как и тело человека, вроде бы симметричны, однако это не означает равноценность правого и левого полушарий в каких бы то ни было отношениях. Функции управления органами нашего тела и сложные психологические функции человека несимметрично распределены между полушариями. Каждое полушарие может воспринимать, 
заучивать, вспоминать и чувствовать независимо от другого, но в способе обращения с входящей информацией между ними имеются существенные различия.

Если левое полушарие воспринимает зрительный образ расчленено, аналитически, то правое- конкретно, сразу во всех подробностях. Правое полушарие обеспечивает конкретно-образное мышление, в том числе интуитивное. Левое полушарие обеспечивает абстрактное мышление являющееся высшей формой логического.

Воспринимая зрительные образы по- разному, оба полушария осуществляют «сотрудничество», в результате которого в нашем сознании формируется мысленный, абстрактный, субъективный образ. Причем правое полушарие быстрее, чем левое, перерабатывает любую поступающую информацию. А результаты образного мышления анализируются умом левого полушария и затем оформляются в речь.

\section{Полушарие}

\begin{tabular}{l}
\multicolumn{1}{c}{ Левое } \\
Логика \\
Последовательность \\
Символы \\
Разум \\
Речь \\
Язык \\
Числа \\
Конкретное \\
Обособленность \\
Рациональность
\end{tabular}

Правое
Интуиция
Одновременность
Образы
Чувства
Ритм
Цвет
Мечты
Абстрактное
Единство
Воображение

Существующая система образования строится исключительно на развитии способностей левого полушария, т.е. логического мышления. И наши утверждения, что мы развиваем творческое мышление учащихся, остаются словами, лишенными реального содержания.

Весь западный мир, с которого мы пытаемся брать пример и делать заимствования, в том числе педагогические - это левополушарная цивилизация, породившая ряд глобальных проблем - экологических, энергетических и других.

А ведь у нас в стране и даже в нашем городе есть прекрасные педагогические идеи, основанные на последних достижениях в области нейронауки. По моему глубокому убеждению, в современное время как никогда востребована методика Б.И. Вершинина, Народного учителя СССР, долгие годы работавшего в школе №12 города Томска. Им разработана система обучения, позволяющая сделать процесс познания естественным, обополушарным. Так же подобные идеи высказаны и развиты Л,Е. Поповым, профессором ТГАСУ, доктором физико-математических наук.

Обучение должно быть ориентировано на интактный мозг, ибо мышление, эмоции, память, обеспечиваются совместной работой двух полушарий. Исходя из того, что информация кодируется мозгом как минимум дважды: в виде образов и их словесных аналогов, а её анализ и синтез осуществляются при совместном участии правого и левого полушарий, познавательный процесс должен быть полицикличным.

При применении данной методике мы должны получить как раз то, что называется образованием. А по меткому выражению физика М. Лауэ: «Образование есть то, что остается, когда все выученное уже забыто». 
Знакомство с методикой Б.И. Вершинина, встречи с Л.Е. Поповым подвигли автора этой статьи к применению фрагментов данной методики в преподавании общественных дисциплин- истории и обществознания.

Как показал мой опыт, применять технологию включения образного мышления целесообразно при постановке задачи увидеть и проследить причинно-следственные связи изучаемого явления.

Например, при изучении темы «Политическая раздробленность Руси» в 10 классе нужно вскрыть причины данного явления. Причины эти описаны в начале параграфа, предваряя фактологические данные. Учащимся предлагается взять пластилин? и вылепить! причины феодальной раздробленности, а именно:

1. Развитие производительных сил, прогресс сельского хозяйства, ремесла, торговли, т.е показать экономическую самостоятельность отдельных княжеств.

2. Отсутствие единой политической власти, т.е политическую самостоятельность отдельных княжеств.

3. Геополитическую обстановку, т.е. угрозы извне или их отсутствие.

4. Упадок торгового пути « из варяг в греки».

5. Разделы и переделы земель между князьями, т.е. междоусобные войны.

Поначалу задание вызывает ступор и недоумение, у некоторых наблюдается отрицательная реакция, дескать «как это», «не могу и не буду», «детский сад» и т.д. Но, постепенно втянувшись в работу, не замечают даже, что окончился урок. По прошествии определённого времени, когда большинство справилось с заданием, листы с каждой парты, на которых вылеплены причины (без всякой абстракции), кладутся на сдвинутые 3-4 парты и получается одна общая картина изучаемого исторического явления.

Что характерно, спустя многие месяцы, учащиеся помнят вышеупомянутые причины.

Учитывая ограниченность во времени, данную методику рекомендуется применять лишь при рассмотрении ключевых тем на вскрытие причинно-следственных связей и не злоупотреблять ею. Эффект достигается при неоднократном систематическом применении в сочетании с другими видами учебной деятельности.

В качестве наглядного примера данный метод можно использовать при рассмотрении причин войн или революций. Например, предложить вылепить или хотя бы нарисовать причину Первой русской революции, а именно:

1. Нерешённость земельного вопроса,

2. Нерешённость рабочего вопроса,

3. Нерешенность национального вопроса,

4. Проигранная русско-японская война.

или причину революции 1917 года.

По обществознанию для рисования и лепки подойдут такие вопросы, как причины инфляции, устройство банковской системы, причины безработицы, социальная структура общества, социальные взаимодействия, политическая система, гражданское общество и государство и т.д., для проявления творчества тем предостаточно.

\section{Список литературы:}

1. Вершинин Б.И. Мозг и обучение. Методика реализации функциональных возможностей мозга. [Текст] / Б.И.Вершинин. - Томск, 2007. 
2. Вершинин Б.И., Попов Л.Е., Постников С.Н., Слободской М.И. Состояние души. Беседы о педагогике как науке о путях реализации функциональных возможностей мозга. [ Текст ] / Б.И. Вершинин., Л.Е.Попов, С.Н. Постников, М.И.Слободской. - Томск, 2006.

Приложение 1

Работы учащихся на тему: «Причины феодальной раздробленности»
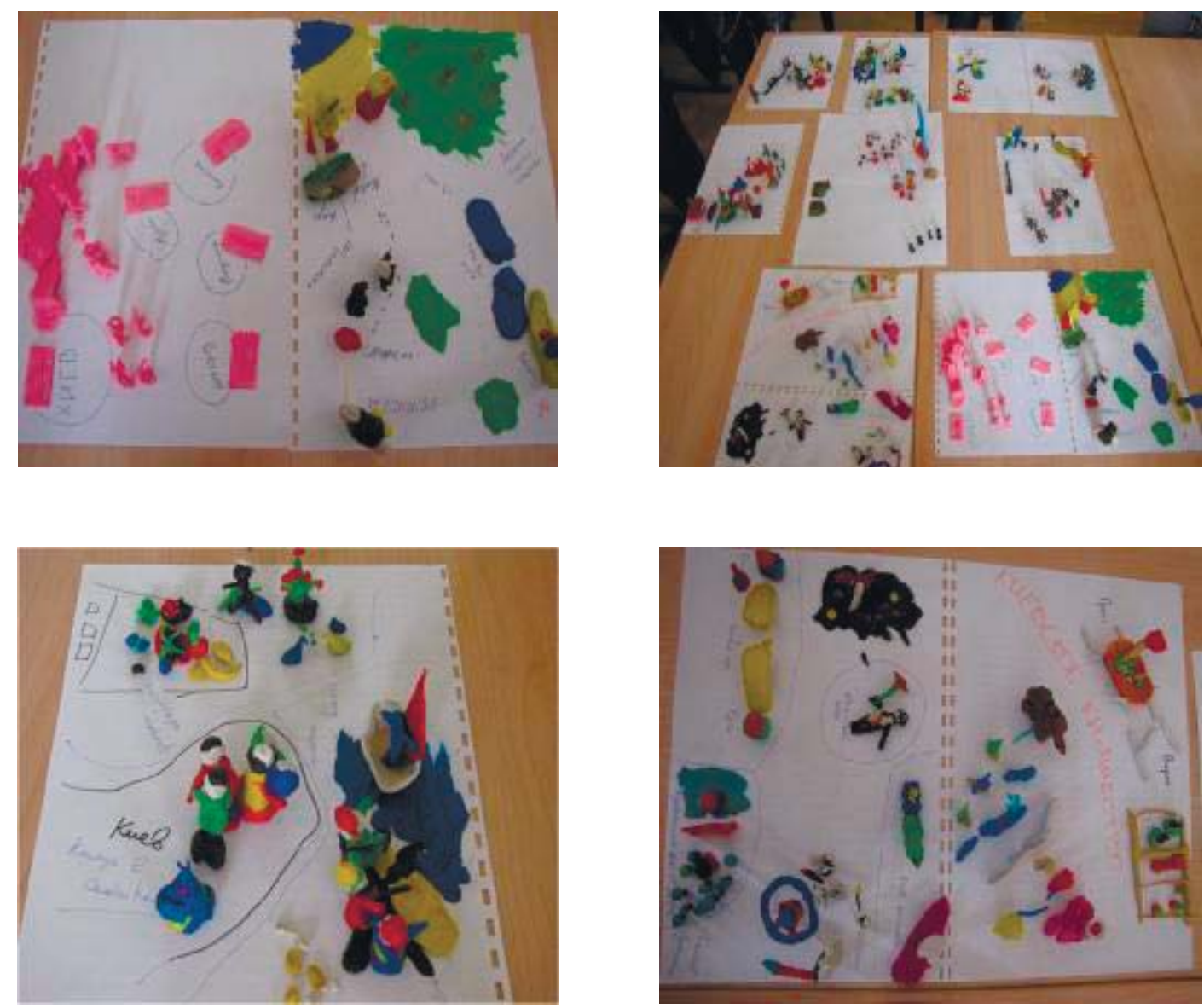

\section{Собственный сайт отеля как особый вид EDS и инструмент продажи} гостиничных услуг

Чернов Д.С., магистрант, Санкт-Петербургский государственный экономический университет,

2. Санкт-Петербург

E-mail: helene8@yandex.ru

Научный руководитель: к.с.н., доцент Печерица Е.В.

Учитывая темпы прогрессивного развития индустрии гостеприимства и туристического рынка, сайт отеля становится не только визитной карточкой объекта, но и эффективным каналом продаж. Основная задача официального сайта гостиницы обеспечить клиента всей необходимой информацией об объекте, предоставить 